Charles Forceville*

\title{
Compasses, beauty queens and other PCs: Pictorial metaphors in computer advertisements
}

\begin{abstract}
Computer advertisements make extensive use of pictorial metaphors. The model proposed in Forceville (1996) is used as a starting point to analyze 27 advertisements in $P C$ Magazine, July/August 1999 (American edition) that contain a pictorial metaphor. The aim is twofold: (1) to further contribute to the theory of pictorial metaphor by testing the model against a new corpus; (2) to make an inventory of the source domains used in the metaphors, and thereby tomake some observations about the ways in which representations of computer technology interact with our daily lives.
\end{abstract}

\section{Introduction}

The first task of an advertisement is to draw attention to itself. If it is not noticed, neither will, by definition, the product advertised in it, let alone that any positive claims made for it will be processed. One way for admakers to increase the chance that the consumer's eye will remain hooked to their ad in the ocean of commercial messages is to incorporate a striking picture. If a product is inherently beautiful - as some types of cars, furniture, and other design toys are thought to be - simply depicting the product itself may attract viewers' attention and persuade them to process the entire ad. But not all products lend themselves to this strategy. Although computer equipment may be designed in a sophisticated manner, PC brands are difficult to distinguish from one another visually. It is thus smart to promote PC equipment by inserting an unexpected picture, that is, a picture from a different realm than that of computing or information technology itself. Alternatively, an unexpected verbal heading can jolt the reader leafing through a mag-

* Charles Forceville

University of Amsterdam

Dept. of Film \& TV Studies

Nieuwe Doelenstraat 16

1012 MA Amsterdam

The Netherlands

E-mail: Charles.Forceville@hum.uva.nl

Hermes, Journal of Linguistics no. $24-2000$ 
azine into paying attention. But the striking picture (or the unexpected heading) must still somehow make sense in the context of the promotional purpose of the ad. One way of ensuring this is to establish a metaphorical connection between the product advertised and the person, thing, or activity suggested by the surprising picture or the unconventional text. Using a pictorial metaphor is thus an economical way of both attracting attention and making a positive claim about a product.

It is probably because of the boring visual similarity between computer products of different brands that this branch appears to be particularly prone to using pictorial metaphors in its advertising. ${ }^{1}$ My focus in this article is a double one. First, I will chart and analyze source domains employed in pictorial metaphors all used to promote roughly the same product, namely computer equipment and technology. Doing so will allow me to further test my own theoretical model of pictorial metaphor (Forceville 1996) and suggest some refinements where this appears appropriate. Second, analyzing the source domains employed in pictorial metaphors promoting a certain product will help us gain insight into how that certain product (here: computer equipment) is conceptualized in our society.

\section{Preliminaries}

The materials examined in this article consist of some two dozen advertisements promoting computer equipment in a computer journal, $P C$ Magazine (July/August 1999, American edition), which all employ a pictorial metaphor in the sense defined by Forceville (1996). The small and unrepresentative nature of the sample and a degree of inevitable subjectivity I will bring to the analyses clearly impose limitations on the generalizability of whatever conclusions can be drawn. I cannot claim to discuss all the pictorial metaphors in the issue of PC Magazine,

1 Carlo Grevy, editor of Hermes, first drew my attention to this phenomenon, and invited me to write this article. I have much benefited from several discussions we had at the 6th International Cognitive Linguistics Conference in Stockholm (July 1999). I am also indebted to my colleague André Waardenburg (University of Amsterdam) and to Edo Marinus (Cambridge University) for commenting upon the ads to be discussed with more computer-wise eyes than I possess. I also want to thank, yet again, Lachlan Mackenzie (Vrije Universiteit Amsterdam) for his critical reading of my work. This article has improved thanks to them; but of course I alone remain responsible for its errors and oversights. 
or that those I examine are investigated exhaustively. Not only is it sometimes a matter of debate, as will transpire, whether a certain phenomenon qualifies as a pictorial metaphor, but most pictorial metaphors are so rich that they could be discussed at far greater length than is possible here. But I firmly believe that case studies are indispensable for further developments in the fledgling theory of pictorial metaphor.

A few other clarifications are in order. First, I consider advertisements (or any other images) to contain rather than to be pictorial metaphors. Just as sentences or texts can incorporate metaphors without being reducible to them, so there are usually more meaningful elements in an image than the pictorial metaphor it may contain. Print advertisements are word \& image texts, and I will pay attention to the "word" part mainly insofar as it is relevant to the analysis of the pictorial metaphor at stake. Moreover, many elements of the advertisements' design (fonts, deviant patterns of ordering text blocks, the use of colour, etc.) often contribute to the overall meaning, but I will only occasionally mention these here. Secondly, meaning is always meaning to someone (see Sperber \& Wilson 1986: 142 ff., Johnson 1987: 177, Shore 1996: 334). In certain cases, prolonged examination of a source domain, combined with a viewer's personal or cultural cognitive make-up, will lead to the processing of alternative, or additional, mappings from source to target domain. These mappings, then, allow for some freedom of interpretation, but are always constrained by the circumstance that advertisements always claim something positive for the product or service.

In the next section the advertisements discussed are described. The following questions guide the analyses: Which are the target and source domains of the metaphor respectively? Which is/are the feature(s) mapped from source to target? What type of pictorial metaphor is at stake: a metaphor with one pictorially present term (MP1)?; a metaphor with two pictorially present terms (MP2)?; a simile?; or a verbo-pictorial metaphor (VPM)? Very briefly, the four types can be distinguished as follows. In an MP1 only one of the two terms (target and source) of the pictorial metaphor is depicted, while the other term is suggested by the pictorial context. An MP2 is a hybrid pictorially conflating elements of both target and source domains. A simile juxtaposes the two terms without physically merging them; and a verbo-pictorial metaphor (which strictly speaking is no longer a purely pictorial metaphor but rather a multi-media metaphor) represents one term visually and the 
other verbally. As holds for most categories, these are not watertight either, and some specimens hover between types. The nature of the four main types will become more transparent in the discussion of specific examples. For more detailed discussion see Forceville (1996: chapter 6).

\section{Description of advertisements}

1. Hewlett Packard (i) (pp. 2-3). A beautifully coloured beetle with shining exterior and dangerous-looking legs and antennae, displayed vertically, is partly hidden from sight by a vertically displayed notebook. The body copy runs:

Heat. Vibration. Shock. Gravity.

All conspire to destroy the things that stand in their way.

Every PC we make is tested against these forces of nature.

For our notebooks, it's merely preparation

to do battle with the most malicious menace of all:

the road.

The metaphor is NOTEBOOK IS LIKE BEETLE. The metaphorical connection is suggested by their proximity, their shared verticality, and the body-copy. The "shock-proofness" of the beetle, apparent in its natural protection and its ability to survive, perhaps despite its relatively small size, are features that are mapped from BEETLE to NOTEBOOK. It is interesting to speculate how necessary the body copy is for deciding on metaphorical construal. Since the two phenomena are printed against an empty, white background, there seems to be no other justification for their co-presence in an advertisement for computers. But the text is helpful, possibly even necessary, for establishing the mappable features. Since both elements are depicted independently (although the notebook partly overlaps the beetle) this is what I have classified as a pictorial simile (Forceville 1996: 136ff.). ${ }^{2}$

2. Oracle (i) (p. 11). The ad shows a smiling black girl in a silvershining astronaut's suit and a helmet under her arm. A small gloss says, "Tanya, age 9." The heading (in handwriting) runs, "My sisters hog

2 Pictorial metaphors of the simile type are indicated verbally as A IS LIKE B, rather than as A IS B. 
every inch of our bedroom, but every day on the Internet I get a billion miles of space." The body copy tells how Oracle helps schools in an underdeveloped area in Los Angeles by donating computers and Internet connections to aid education. The metaphor can be verbalized as INTERNET USER IS AN ASTRONAUT. Mappable features include, say, "having the opportunity to explore new spaces," where the notion of "space" itself metonymically denotes the latent knowledge and discoveries it harbours. And of course the cosmic and virtual space contrast with the girl's very limited literal "space" at home. The type of metaphor used here is a verbo-pictorial metaphor (VPM): if all text is stripped away, there is no longer a metaphor - just a picture of a smiling girl in an astronaut's suit. Conversely, without the picture, there is nothing that suggests an astronaut, or cosmic space.

3. NTI (p. 14). The ad promotes a file back-up system. A CD-ROM player drawn in cartoon-style points with a human-like right arm to its opened tray. A thought balloon coming from it says, "I want my NTI!" The metaphor is CD-ROM IS HUMANOID CREATURE, and the mapped feature "having human desires such as hunger." A second cartoon picture shows a person with a chef's hat with "NTI" printed on it and an apron with the text "Digital Dan," holding a disk in his left hand. A text balloon coming from him says: "Do more with your CDR/RW drive!" The disk thus becomes some sort of pizza or pancake or doughnut (DISK IS FOOD), to be inserted in the open "mouth" of the apparatus. ${ }^{3}$ The metaphor CD-ROM IS HUMANOID CREATURE is a metaphor with two pictorially present terms (MP2), that is, a hybrid featuring elements of both target and source, whereas the DISK IS FOOD is a metaphor with one pictorially present term (MP1): the disk is "transformed" into, say, a pizza only because of the contextual suggestion that it is held by a "cook" and is to be inserted into a "hungry mouth."

4. SAG electronics (p. 22-23). Two servers are juxtaposed, the left one with a red sash saying "sag's quad xeon," the right one with a blue sash with the text "IBM's netfinity 7000." The heading runs, "Sag VS IBM.... In a head-to-head match, the two servers 'earned virtually iden-

3 Computer geeks apparently use the expression "burning a CD Rom," which would explain the choice of metaphor here. I owe this observation to Edo Marinus. 
tical scores.' But, IBM cost $43 \%$ more! ... So, Who's the true winner?" (a note indicates the quoted qualification came from a recent PC Computing test report). The sashes personify the servers: SERVERS ARE CONTENDERS (whether athletes or racing-car drivers (MP1)), which endows the servers with human desires - here the desire to win. Another way to "see" the metaphor, incidentally, is as SERVERS ARE RIVAL BEAUTY QUEENS, since sashes are used for winners of beauty contests as well. The colours of the sashes were no doubt chosen advisedly: the "blue" of IBM recalls "Big Blue"; the "red" of SAG is the colour that also dominates the background of the ad.

5. Umax (p. 25, fig. 1). The photo offers a frontal, low angle view of a UMAX computer, displayed vertically, which is surrounded by a yellow "haze." A text balloon coming from it declares, "Power On." Underneath, three (of four) supports are visible. Since the supports also occur in the small-size picture in the left-hand bottom corner of the ad, which again displays the equipment, we may assume they are indeed part of the machine. In combination with the text balloon, which personifies the machine, the supports acquire foot-like qualities. The fact that there are four rather than two "feet" inclines one to think of the source domain of ROBOTS rather than HUMANS. The yellow haze, too, adds to the science-fictionlike atmosphere of the robotic domain; or alternatively as a halo-effect suggesting a miraculous "apparition" (the latter impression is also strengthened by the fact that the machine is depicted slightly from below, enhancing its "power"). The metaphor should therefore be construed as PC IS HUMANOID ROBOT rather than PC IS PERSON. If this construal is accepted, the feature mapped arguably is "being ready to serve." The type of metaphor at stake wavers between VPM (the text balloon is the strongest cue of personification) and MP1 (the pictorial context - "feet," yellow haze, and lowangle photography — may be understood as suggesting the personification independently of the text balloon). 

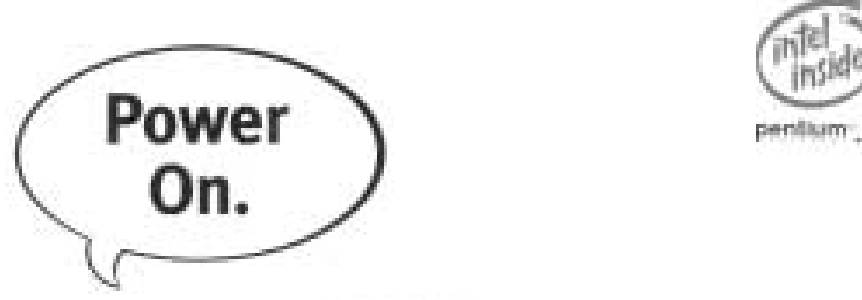

pertium ...

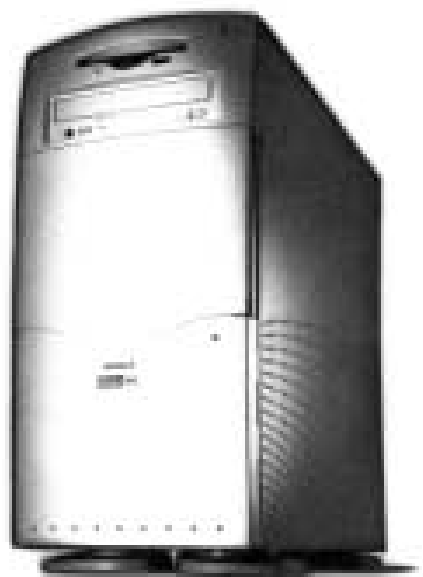

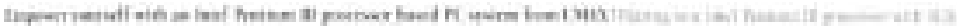

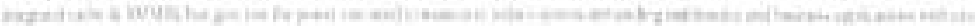

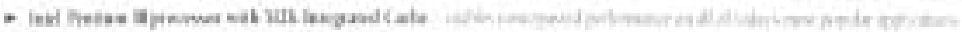

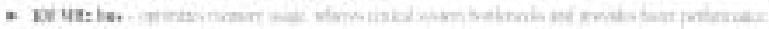

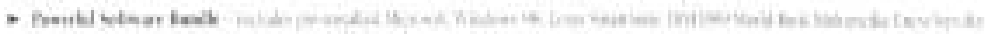

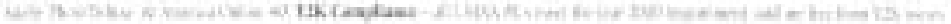

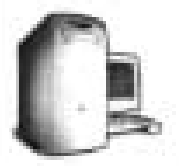

\begin{tabular}{|c|c|c|}
\hline (स) & $\cos x$ & $m$ \\
\hline$=$ mins. & $\operatorname{mas}$ & ine mat \\
\hline
\end{tabular}

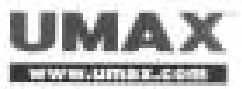

Fig. 1. Umax (PC Magazine, August 1999, p. 25): PC IS HUMANOID ROBOT 
6. HewLett Packard (ii) (pp. 32-33). Through the hole in the middle of a three-blade ship's propeller we see fragments of PC equipment. The body-copy contains phrases like "Water displaced creates forward thrust. ... The beginning of voyage. ... Where would you journey?

Toward the edge of imagination? Our PC workstations are waiting to speed you there." A metaphor of the simile type can be construed: PC EQUIPMENT IS LIKE A SHIP'S PROPELLER, with as mapped feature "providing the means to make progress."

7. Canon (pp. 38-39). A printer is depicted with a handle, carried by a partly visible male arm. The heading, "Any more portable and it would carry itself," clearly signals the metaphor PRINTER IS BRIEFCASE, while the mapped feature is "portability." The phenomenon is a hybrid, and is thus to be classified in the MP2 category.

8. Intel (between pp. 48-49, fig. 2). The picture shows part of a musical score in which the sets of notes, connected by strokes, "consist" of miniature elements of linked PC equipment in various colours. There are verbal inscriptions as well: "Windows NT/NetWare 5.0," "Increase control," "Increase server uptime" etc. (where a real score has terms such as "presto" and "vivace"); and "hairpins" for crescendo and diminuendo. The heading is, "make it all come together, Maestro," and another textual insert runs, "The Intel LANDesk product family. Helping you take control of mixed environments." The body-copy expands on the musical source domain:

Your networked PCs and servers are quite a diverse composition. ...

This essential package inventories PC components, monitors PC health and provides alert notification [!]. ... Combine these solutions seamlessly and your network is sure to give a crowd-pleasing performance.

The metaphor could be verbalized as: COMBINATIONS OF COMPUTER COMPONENTS ARE NOTES IN A MUSICAL COMPOSITION, with as mapped features, say, the need to ensure perfect timing, the performance of creative processes, and the continuous changing of configurations. The person responsible for the smooth interaction of the various machine is metaphorically (and flatteringly) addressed as the "Maestro." The metaphor is closer to an MP2 than to a VPM. 


\section{Make it all come together, Maestro.}
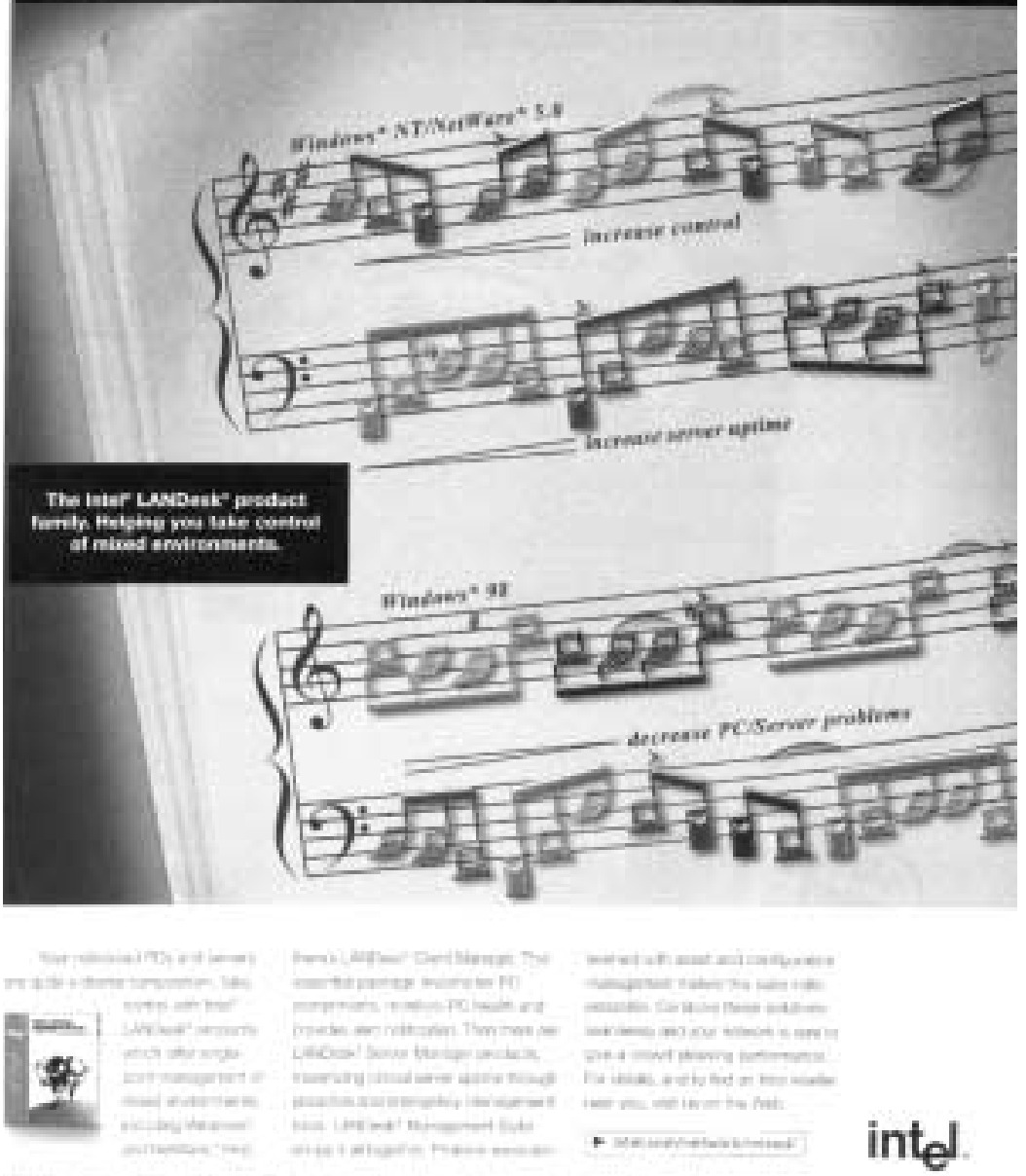

inted.

Fig. 2. Intel (PC Magazine, August 1999, between pp. 48-49): COMBINATIONS OF COMPUTER COMPONENTS ARE NOTES IN A MUSICAL COMPOSITION 
9. Macromedia (p. 72). The picture shows a dazzling, silver-coloured car, headed by the text "Flash helps millions of hearts race daily," and contains the slogan "add life to the web." The product is software that helps one download, for instance, images found in other websites. One interpretation of the picture, guided by the body copy, is clearly that the software was instrumental in downloading and printing a picture of this flashy car. But it is possible to construe a VPM as well: FLASH SOFTWARE IS DAZZLING CAR, with as the mapped feature, "sure to excite users (in the target domain: browsers)." The message is also supported by the pun on "racing."

10. IBM (p. 75). This striking but somewhat enigmatic ad shows an IBM notebook into which a round, silver-coloured saw-blade seems to be quasi-inserted (like a disk). The heading runs: "the new thinkpad 570. (dramatization)." The construal DISK IS SAW-BLADE, an MP2, seems inescapable - but what could be the mapped feature? The first connotation adhering to a saw is surely "sawing" - which in the present context is a highly destructive activity. When one scrutinizes the body copy, one comes across the section: "This is how it works. Slip the ultralight, superthin ThinkPad 570 into an UltraBase and it transforms into an all-in-one desktop ready for the office or the road." Presumably we are to understand that the notebook is so thin that it takes saw-bladethin disks, while the saw's presence is also "realistically" motivated for having created an even thinner notebook.

11. Hewlett Packard (iii) (pp. 116-17, fig. 3). The photograph represents an awe-inspiring samurai-like fighter wearing an impressive helmet and armour, who holds a sword in front of himself, looking offscreen right; in front of the swordsman, and partly hiding him from sight, a vertically displayed (part of a) PC is visible. The text, in a layout similar to that of HP examples 1 and 6 begins "Protector./ Defender./ Sentinel." and refers to a "a consortium of security features that guard your/ vulnerable data." The simile is PC IS LIKE GUARDSMAN, and the mapped feature is "providing protection." 


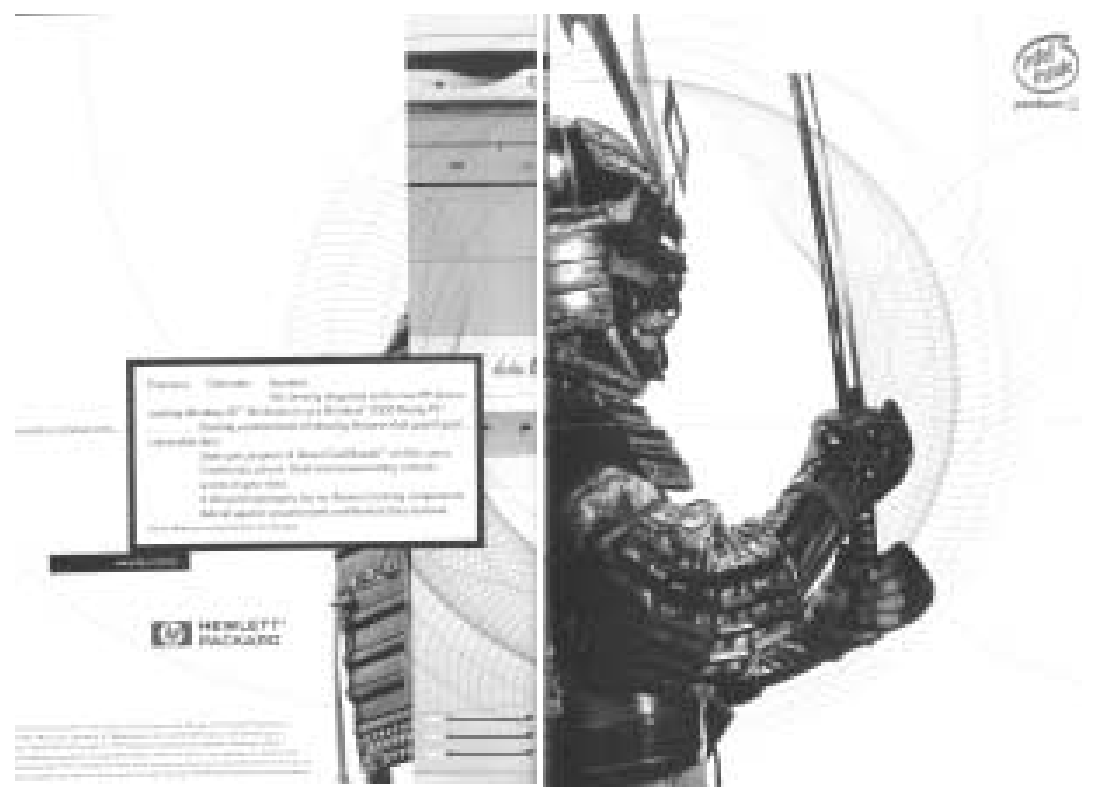

Fig. 3. Hewlett Packard (PC Magazine, August 1999, p. 116-17): PC IS LIKE GUARDSMAN

12. Hewlett Packard (iv) (pp. 118-19). The picture portrays what appears to be a high-tech style gyroscope with a goldenish rim, displayed next to a PC. The text mentions "a meditation of movement and balance, the new HP Vectra PCs, running/ Windows NT Workstation, are steady customers in the juggling act called/ Stability./ Substantiated by:/ Consistent components so you never need to change your gold disk." The metaphor PC IS LIKE GYROSCOPE is a simile, as are the earlier HP examples discussed, and the mapped feature, say, "maintaining stability in a situation of constant movement."

13. Xircom (p. 149). The picture shows the corner of a suitcase, where the end of a cable is squeezed by the suitcase's zipper. The text runs "Dongle caught in your zipper?" The product is a PC Card solution for making unbreakable connections. The VPM, DONGLE IS PENIS (backed up by the slang word "dong" meaning "penis"), invokes a painful male problem. The mapped feature is, "running the risk of getting caught in, and damaged by, external forces." 
14. Hewlett Packard (v) (p. 157). The picture displays part of a dressmaker's model on whose body and head there are many numbered dots (acupuncture spots?), connected by curved lines. In front of the model is a PC. The body-copy contains lines such as "Corporation. From corporeal. A body given life by your network./ The grid of connections carrying the life force, information, throughout/ the meridians of your business. Products like this desktop PC help keep your company healthy." Given that this specific HP ad promotes "HP Vectra corporate PCs," the resulting simile is A PC NETWORK IS LIKE A HUMAN BODY, and the mapped feature something like "the interconnectedness of vital elements." Note that the interpretation of this metaphor depends strongly on the body copy.

15. Iomega (p. 158). A card drive is shown carrying the text "iomega/ CLIK!/ PC Card Drive" and the red/white iomega logo. The card drive appears on a texture-like dotted blue-on-black background, covering most of its rectangular silver. There is also a white arrow pointing upwards. The object lies half on top of, again, a blue-on-black background that could be part of the upholstery in a car. In front of the card drive lies a clik! diskette. The heading is, "With a little drive, you can really go places." The body-copy begins,

The amazing Clik! PC Card drive and $40 \mathrm{MB}$ disks. Tiny laptop storage that goes a long way. We've just changed the shape of portable laptop storage. The new Clik! drive actually disappears right into your laptop's PC Card slot then accepts the 2"x 2", 40 MB disks. This is portable storage at its best. Convenient, cordless, easy to carry, easy to use, and affordable. ...

The metaphor, suggested both by the visual properties of the card drive, the heading, and the name "Clik" is PC CARD DRIVE IS SEATBELT. Whereas one would probably infer "safety" as the mappable feature, this concept is mentioned nowhere in the body copy. So probably it is the ease with which one clicks on one's seatbelt which is the quality projected onto the way the drive and disk fit into a PC. But given the salience of the property "safety" in a seatbelt, I speculate that at least some viewers will also see it as participating in the metaphorical mapping. Of course the double meaning of "drive" is punned on as well. In addition to, or instead of, construing a metaphor one could understand the seatbelt as an "illustration" cueing the word "drive." The construal 
of the metaphorical source domain depends strongly on verbal cues, so it should probably be classified as a VPM rather than as an MP2.

16. Compaq (pp. 160-63). A man sits in front of a PC and smiles at its screen, which displays pictures of various Compaq products. The heading runs, "It's like this. You're the kid./ We're the candy store." This VPM, which is further cued in the body copy, can be phrased as BUYING A COMPAQ PC AS AN ADULT IS BUYING CANDY AS A CHILD, and the mapped features include the width of choice and a strong desire to buy. Moreover, there is a suggestion of low cost involved in the buying. Notice that thanks to the metaphor the PC screen in the picture acquires elements of a shopwindow.

17. Powerquest (p. 167). The picture shows two surgeons, with covered mouths, bent over an opened PC. They have tools in their hands and are working on the PC's hard disk. One of them is sweating. Through a window in the door an anguished person (the PC's owner?) is watching the operation. The heading: "With Lost \& Found, recovering your lost data doesn't have to be a difficult operation." The body copy further elaborates on the MP1 PC IS PATIENT, which perhaps more specifically focuses on HARD DRIVE IS HEART.

18. OnStream (p. 169). The picture shows a deserted country road with on the right a green field with a board saying "For Sale/ 329,620 Acres/ \$39." Underneath/left a picture of a digital drive and the text "30 GB Digital Drives/ From \$299." The body copy begins, "Big space at a small price. That's the idea behind the OnStream 30GB and 50GB digital storage solutions." The verbo-pictorial metaphor is VIRTUAL SPACE IS REAL SPACE, and the mapping pertains to the availability and cheapness of space.

19. Hewlett Packard (vi) (p. 171). In this advertisement, HP juxtaposes three vertically arranged coloured circles (red, yellow, and green) which upon a moment's reflection (or upon reading the text) reveal themselves as traffic lights - with a netserver, also displayed vertically. The body-copy includes the following "Motoring along in your business, / you drive up to the HP NetServer E60. ... Auto Alert monitors the hard drive, using/ traffic lights ... to signal its status. yellow? red?/ A quick look informs you what to do to keep things running/ smooth. Green light. Nothing to worry about. ..." This simile can be verbalized 
as SERVER'S REGULATING SYSTEM IS LIKE TRAFFIC LIGHTS. Note that the three colours of the traffic light are also used on the machine itself, as the body-copy tells us, so that the source domain of the metaphor is "naturalized": the lights occur literally on the machine. The mapping can be phrased as "giving signals to allow for smooth and safe progress."

20. ELSA (p. 173, fig. 4). A black/white photograph shows a smiling man, right hand on his hip and standing on his right foot, in the process of putting his stretched left foot forward. He balances a piece of computer technology (as the body-copy informs us: a graphic accelerator card) on the index finger of his left hand. The heading tells us, "Above all, Elsa." The body copy promises

Yes! You can create PowerPoint presentations and speed through business applications in a fraction of the time. ... The new Elsa ERAZOR III graphic accelerator card [is] powered by the astonishing technology of ELSA and the nVidia RIVA TNT 2 processor. Together they turn your PC into a high performance productivity center. ... Virtually any kind of business presentation in record time. ...

While it is not necessary to see anything metaphorical in this advertisement other than the deeply entrenched metaphor GOOD IS UP (Lakoff \& Johnson 1980: 16), the smiling man's posture, combined with several phrases in the body copy, suggests something of a virtuoso performance or magician's trick. Hence a pictorial metaphor can be construed; say, ELSA USER IS MAGICIAN. But metaphorical construal is not imperative. The man could be seen as merely pointing to the accelerator card rather than balancing it on the tip of his finger, and together with the conventional GOOD IS UP metaphor this would provide at least a partial realistic motivation for the picture. But if we see the ELSA USER IS MAGICIAN/ PERFORMER metaphor, the mapping would be something like: "effortlessly capable of difficult tricks or feats." It is not completely clear how the metaphor should be categorized. If we decide to label "posture" an element of context, this is an MP1; but if it is understood as part of the domain of the magician/performer, it should be called an MP2. 


\section{ABDVE}

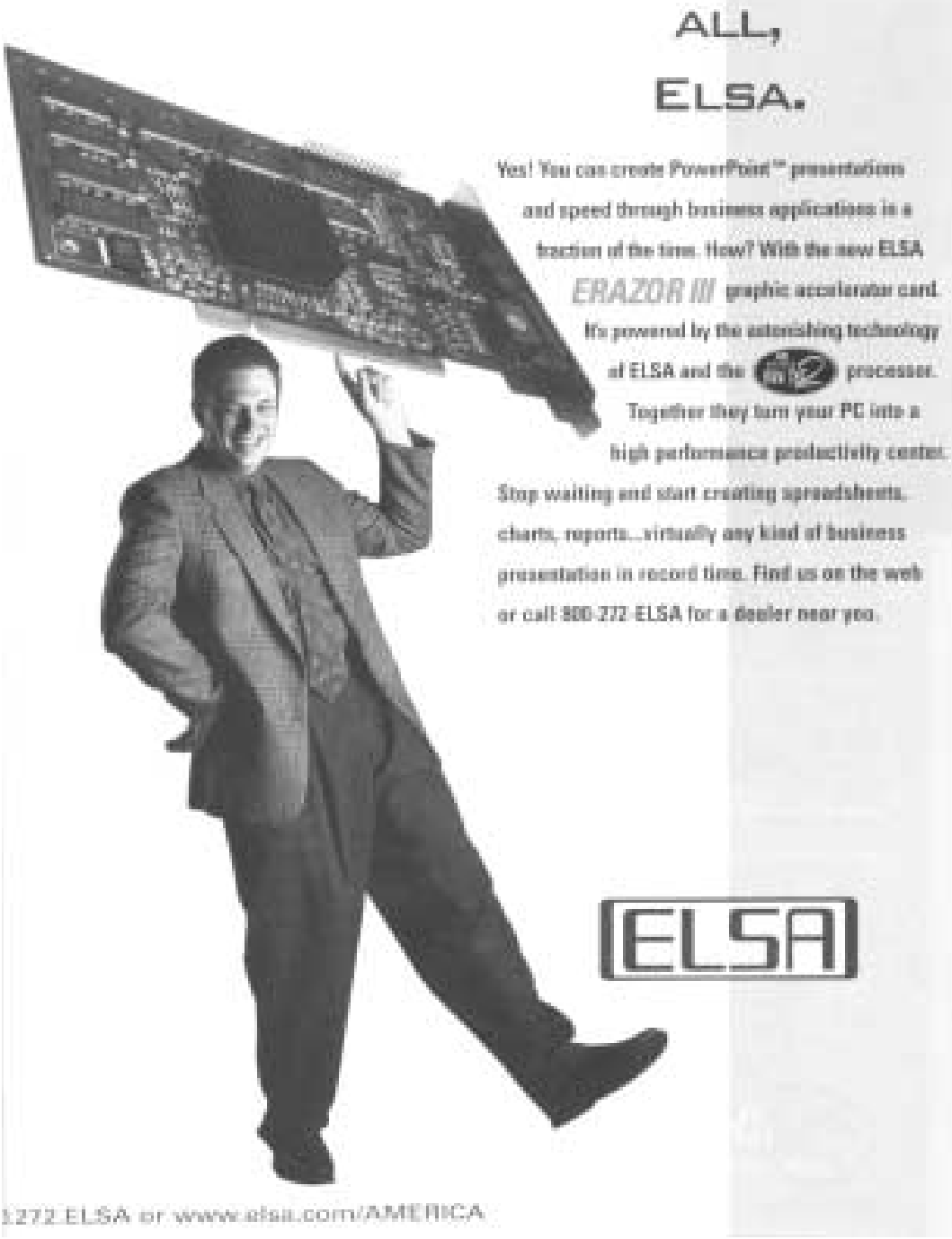

Fig. 4. ELSA (PC Magazine, August 1999, p. 173): ELSA USER IS MAGICIAN 
21. Oracle (ii) (p. 184). A white "crying" mask lies next to a "laughing" mask. Both masks have ribbons (black and red respectively), presumably to attach them to a face. The heading over these masks asks, "Unhappy with the personality of your database?" The word "personality," the laughing mask's ribbons, and the Oracle logo are all in red. The body-copy emphasizes the Oracle8i's versatility. "It can be a Web server, a file system - in fact, anything you want it to be." Hence, the metaphor is COMPUTER IS VERSATILE PERSON or COMPUTER IS ACTOR. The mappings of this VPM are variability, changeability, adaptability. Moreover, the notion of "magic" is an important element as well, while the connotations of dramatic art bestow an element of cultural prestige to the machine.

22. Toshiba (i) (pp. $212+217$ [sic]). An opened notebook is seen balancing on one of its corners, throwing as its shadow a pair of compasses. The heading runs, "Pure power. Pure portability. Pure precision." Product information is given under four sub-headings: "Powerful; Productive; Flexible Expansion; Ultra-thin. Ultra-light," and these encapsulate the mappings from source to target in the simile NOTEBOOK IS LIKE PAIR OF COMPASSES. Once more, the link between the two domains is not completely arbitrary; there is a realistic motivation for the compasses in that these supposedly embody a thrown shadow although of course this is only a very rough approximation.

23. Toshiba (ii) (pp. 215-16). Drawing on the same concept as the previous Toshiba ad, the shadow thrown in this simile is that of the king in a chess game (NOTEBOOK IS LIKE CHESS KING). The mappings can be found in the heading ("The ultimate strategy for power and performance") and under the sub-headings with further product information: "Cutting-edge performance; One motherboard. One image; 12,600 possible configurations; Lower total cost of ownership." (In this final section, the last line is: "And your next move is as simple as calling 1-800-TOSHIBA or clicking on www.toshiba.com.") As in the previous ad, there is a (weak) aspect of realistic motivation for the connection between target and source domain because of the shadow.

24. Microsoft (pp. 262-63). The picture shows an ordinary breadknife which is used as a screwdriver to get a four-side screw into a wall. The heading runs, "Surprisingly, people are still building Office solutions without Office 2000 Developer," which results in the VPM: USING 
OFFICE SOLUTIONS WITHOUT OFFICE 2000 DEVELOPER IS LIKE GETTING A SCREW INTO A WALL WITH A BREADKNIFE. (Note that the picture itself makes use of the MP1 BREADKNIFE IS SCREWDRIVER, but that this metaphor does not access the relevant level of processing the ad as a whole.) The mapped feature is the unsuitability of the instrument used.

25. Kensington (p. 303). The photograph depicts a notebook locked with a Kensington security cable to a bicycle stand on a pavement, next to some six bikes. The text begins, "More than 350,000 notebook computers were stolen last year alone. Too bad really, considering we make a security cable that's easier to use than most bike locks." Once more it is not necessary to identify a metaphor here. Although slightly unusual, one could lock a notebook to a bicycle stand on a sunny day - in fact this would suggest that even when a notebook lies on the street, as long as it is locked with a Kensington cable, it is not likely to be stolen. But the simile NOTEBOOK IS LIKE BIKE can be inferred here, with the mapped feature verbalizable as "prone to being stolen."

26. Dell (back cover). The picture shows three people's heads squeezed against the inside of a computer screen, so that their cheeks have been flattened. The heading runs, "Now inside every PC: A complete support department." The metaphor, an MP2, is VIRTUAL HELPDESK IS GROUP OF PEOPLE. The personification emphasizes a (human) desire to help. It is, again, not imperative to see a metaphor here, since the three people's heads could simply be visible on the screen although the flattened cheeks suggest they are "bodily" there, not as mere representations. 


\begin{tabular}{|c|c|c|c|}
\hline No. & Advertisement & Type & Source Domain \\
\hline 1 & HP (i) & Simile & ANIMAL CREATURE \\
\hline 2 & Oracle (i) & VPM & HUMAN PERSON \\
\hline 3 & $\begin{array}{l}\text { NTI (a) } \\
\text { NTI (b) }\end{array}$ & $\begin{array}{l}\text { MP2 } \\
\text { MP1 }\end{array}$ & $\begin{array}{l}\text { (a) HUMANOID CREATURE } \\
\text { (b) FOOD }\end{array}$ \\
\hline 4 & SAG & MP1 & HUMAN PERSON \\
\hline 5 & Umax & VPM/MP1 & HUMANOID CREATURE \\
\hline 6 & HP (ii) & Simile & TECHNOLOGY \\
\hline 7 & Canon & MP2 & BUSINESS \\
\hline 8 & Intel & MP2 & MUSICAL ART \\
\hline 9 & Macromedia & VPM & TECHNOLOGY \\
\hline 10 & IBM ThinkPad 570 & MP2 & TECHNOLOGY \\
\hline 11 & HP (iii) & Simile & HUMAN PERSON \\
\hline 12 & HP (iv) & Simile & TECHNOLOGY \\
\hline 13 & Xircom & VPM & HUMAN PERSON \\
\hline 14 & $\mathrm{HP}(\mathrm{v})$ & Simile & HUMAN PERSON \\
\hline 15 & Iomega & MP2 & TECHNOLOGY \\
\hline 16 & Compaq & VPM & CHILDLIKE BEHAVIOUR \\
\hline 17 & Powerquest & MP1 & HUMAN PERSON \\
\hline 18 & OnStream & VPM & SPACE \\
\hline 19 & HP (vi) & Simile & TECHNOLOGY \\
\hline 20 & ELSA & MP1 & MAGIC/ ART \\
\hline 21 & Oracle (ii) & VPM & MAGIC/ ART \\
\hline 22 & Toshiba (i) & Simile & TECHNOLOGY \\
\hline 23 & Toshiba (ii) & Simile & GAMES \\
\hline 24 & Microsoft & VPM (MP1) & TECHNOLOGY \\
\hline 25 & Kensington & Simile & DAILY LIFE \\
\hline 26 & Dell & MP2 & HUMAN PERSON \\
\hline
\end{tabular}

\section{Scheme 1}




\section{Discussion}

\subsection{Comments pertaining to a theory of pictorial metaphor}

Explicitly versus implicitly signalled metaphors. In quite a few of the examples discussed, it appeared that the construal of a metaphor was possible, even probable, but not necessary. That is, in these cases one can justify the juxtaposition of two salient elements in an advertisement without conjecturing a pictorial metaphor. The latter practice, i.e. postulating a metaphorical relationship between elements that do not absolutely require such a connection is what Steen calls "metaphoric processing," as opposed to "metaphor processing" (1994: 44f.), where the latter describes the situation of understanding something as a metaphor that allows for no alternative ways of making sense. The same opposition occurs in a distinction between explicitly and implicitly signalled metaphors I have recently proposed:

The closer a metaphor approximates the "explicit" pole of the continuum, the more it forces its audience to interpret two entities as a metaphorical target and source respectively, and hence the less plausible are alternative explanations for the juxtaposition/identification of the two entities. Conversely, the closer a metaphor approximates the "implicit" pole of the continuum, the more the juxtaposition of two entities can be realistically explained by inferring other reasons than a metaphorical identification between the two entities (Forceville 1999b: 194).

The more self-evidently the salient juxtaposition of elements is interpreted in terms of metaphor, the more explicit it is, and vice versa. But as indicated in the various analyses, a metaphorical and a non-metaphorical reading can co-exist. I have referred to this situation as "realistic motivation," a concept borrowed from film studies (see Bordwell 1985: 36). The point is that the use of a creative metaphor is a highly artificial, self-conscious act of rhetoric. To diminish this artificiality and viewers' concomitant awareness that their responses are strongly manipulated - an admaker can insert cues that make it possible to explain the presence of the metaphor's source domain on realistic (or quasi-realistic) grounds, that is, on grounds other than a metaphorical identity relation. The more realistically motivated a rhetorical device is, I propose, the less aware we tend to be of its manipulative power, and the more "natural" we find the juxtaposition of the two salient elements. Examples of this "naturalization" of what on a metaphoric reading is/ 
would be a source domain occur for instance in no. 2 (the girl could aspire to becoming an astronaut); no. 9 (the software helps one download fine pictures, for instance of a car); no. 15 (the Card Drive is to be inserted into a notebook, typically a piece of equipment used in a car); no. 19 (the traffic lights are literally similar to the lights on the machine); no. 20 (the man may simply be pointing to the accelerator card); no. 25 (a reckless PC owner could literally lock his notebook to a bike rack); no. 26 (the "support people" could be represented with flattened cheeks on the screen rather than be "inside" the computer).

Simile, VPM, MP1, MP2 (see scheme 1); some comments on the different types. As indicated, it is sometimes difficult to classify the metaphors according to type. Some examples can be ranked under two different types. That is, these are not "pure" examples of a type: usually the question is whether the textual anchoring is so strong that without it no metaphor is identifiable, so that the label VPM is in order. Notice that according to the criteria used, the similes discussed are fairly clearcut cases. That is,

removal of the pictorial context - if present in the first place - still allows the reader/viewer to identify both terms. Removing the verbal context again does not affect the identification of the two terms, although it may problematize their characterization as primary subject [= target $]$ and secondary subject [= source] respectively (Forceville 1996: 163).

The three similes discussed in Forceville (1996) have a rather neutral, or even unidentifiable, pictorial context. It is not clear whether this is coincidental, but it may not be so. For one thing, admakers employing similes appear to avoid visually distracting their viewers from the two salient objects; nor do they seem to "need" other objects or events in the pictorial background either to identify the two metaphorical terms or to cue salient properties of either of them. Notice that of the nine similes in the present corpus all six Hewlett Packard similes, and the two Toshiba ones, dispense with context. ${ }^{4}$ Apparently, the starkness of their juxtaposition is enhanced by the absence of context. But what role does the text play? While it may be true that no text is necessary for the identifi-

4 Note that the HP ads all contain curvilinear structures as part of the background. But while these help unify the HP ads in terms of design, they do not, as far as I can see, affect the meaning of the similes. 
cation of the two terms of the simile, ${ }^{5}$ the question is whether they are in all cases processed as a metaphorical target and source without the help of the text. I assume that most western viewers would see the processing as a pictorial simile as the most relevant way to make sense of the juxtaposition even without reading the text, mainly on the basis of the genre-classification of the pictures as advertisements (see Forceville 1999c), but theoretically, other interpretations are possible: "you need to defend your notebook with all possible means" (no. 11) and "Even kings make use of HP notebooks" (no. 23). The ads classified as containing similes, that is, contain two elements that are juxtaposed in such a way that they challenge the viewer to connect them in some way or other, but it may not, without help of the text, be always obvious that the connection must be based on a simile (rather than on a different type of motivation). It is to be observed that only the Kensington simile (no. 25) has pictorial context, and it is this context which, as argued, "naturalizes" the situation and allows for a reasonably plausible non-metaphorical interpretation.

The metaphors classified as VPMs allow the admaker the greatest freedom in the design of the pictorial part, since the depicted term need not be connected with anything else pictorially; and it is easy to link a depicted phenomenon to another phenomenon by means of language. It may be significant that the VPM examples are all used in cases where depiction of two terms would have been difficult or, for some reason, inappropriate. Oracle (i) and OnStream (nos. 2 and 18) sell the concept of virtual space; Macromedia, Oracle (ii), Microsoft (nos. 9, 21, 24) sell "software"; and Xircom (no. 13) could hardly have depicted a male organ as source domain. The one exception is the Compaq ad (no. 16). But without the heading, the ad still makes perfect sense; in this ad, then, (contrary to the other ones) the verbal element adds another layer (that is, it introduces a metaphor), but is not indispensable for comprehension of the advertisement.

The MP2s are, by definition, hybrids. Inasmuch as almost always one of the two terms (usually the target) represents the product, advertisers will be reluctant to use the type, since the construction of a hybrid

5 Although I did not, before reading the body copy, recognize the three coloured circles in no. 17 as traffic lights, while a colleague before reading the body copy in no. 6 identified the picture as a "fan" rather than a "propeller." 
necessarily entails a degree of violation, or corruption of the terms (including, most of the time, the product). From this point of view, it is worth pointing out that in the case of the MP2s in NTI(a), IBM ThinkPad 570, and Dell (nos. 3a, 10, 26) the metaphor does not involve the product advertised itself. Intel (no. 8) again provides a service rather than a depictable single product, and moreover accommodates miniature versions of equipment as part of the musical notes (they appear as the heads of each note), so that the machines are not themselves hybridized. The Canon ad (no. 7) allows a simple handle to be stuck on top of the notebook to transform it into a suitcase. This means that the product itself remains unviolated, while the connotation of "portability" is a cliché of notebooks anyway.

The MP1s depend on pictorial context for the recovery of the second term (usually the source), and therefore require no visual alteration of the target (that is, usually, the product). Notice that two of the four specimens discussed occur in cartoon-drawings (nos $3 \mathrm{~b}$ and 17). Since this type of depiction often carries the connotation "humourous," it is potentially dangerous to use this type of drawing for a "serious" product. But in the case of $3 \mathrm{~b}$, the cartoon context emphasizes down-toearthness, whereas in 17, again, a service is provided that is relevant in acknowledged situations of panic, which makes cartoon depiction seem appropriate. But the MP1s in the SAG (no. 4) and ELSA (no. 20) ads occur in a photograph, so the use of a cartoon in the earlier two ads appears to be coincidental. More research into possible correlations between types of metaphors and illustration techniques seems fruitful (a starting point can be found in Kress \& Van Leeuwen 1996: chapter 7; for a critical review of this study see Forceville 1999a).

\subsection{Comments pertaining to the representation of computer technology in our society}

Source domains used in the metaphors. The source domain of a metaphor used in an advertisement in which the target is a product must be both familiar and evoke positive connotations that are mappable onto that target. It is worthwhile to investigate whether any patterns can be detected in the source domains used in metaphors promoting PC equipment. While it is notoriously difficult and dangerous to construe ad hoc categories without being arbitrary, let me nonetheless speculate on pos- 
sible generalizations. One tendency seems clear-cut: no fewer than seven out of the 27 metaphors present the target domain in terms of a human person (see scheme 1); that is, they are personifications in the narrow sense. If we take the concept of personification in a broader sense, so that it includes animals and androids, we end up with ten cases, which is more than one third. The reader is thus invited to experience computers in terms of fellow-creatures rather than as purely material objects. The other domains are more difficult to categorize. Perhaps it is possible to collect a number of the source domains under the more general heading of "technology": a ship's propeller, a car, traffic lights, a saw, a gyroscope, a seatbelt, compasses, a knife-used-asscrewdriver are all "metal," man-made instruments. There are two sources from the realm of art — music and drama — and one from the realm of games: chess. Of course, since each phenomenon has many connotations (or, in Gibsonian terms, "affordances"), most sources could be put in a different category. For instance, we could categorize car, traffic lights, and seatbelt separately as all belonging to the domain of cardriving. As a matter of fact, many of the source domains would fit into the more inclusive domain of TRAVEL: see for instance nos. 2, 6, 7, 9, $13,15,18,19,25 .{ }^{6}$ But the flashy car in no. 9 could also be perceived as a specimen of "toys-for-the-boys" technology — a notion also hinted at in no. 16. Indeed, if we stop to reflect on it, apart from the personifications, the metaphorical source domains used tend to be associated with what are stereotypically regarded as male rather than as female "worlds." In some cases (nos. 8, 13, 16), men are even explicitly addressed. All this need not surprise us: advertisers try to reach their target audience, and this audience probably consists of more men than women. But the reverse may be true as well: A female readership that potentially belongs to the target audience may be put off by the choice of typically "male" source domains. Another regularity, too, may be observed. Several source domains partake in the "artistic" and/or "magical" and/or "playful." Inasmuch as computer addicts like to see themselves as creative artists rather than as mere rational technologists, these source domains (in nos. 8, 20, 21, 23), too, may be u sed to appeal to a specific readership.

6 I owe this last observation to Carlo Grevy. 
"Backlash" from target to source. Black observes that "if to call a man a wolf is to put him in a special light, we must not forget that the metaphor makes the wolf seem more human than he otherwise would" (Black 1962: 44). This is an intriguing, but hitherto insufficiently investigated claim. Elaborating on Black's work, I have suggested the term "subsidiary transfer" (namely, of features mapped from target to source rather than the primary transfer from source to target) for this type of potentially "reversed" mapping (Forceville 1995; see also Turner 1991: 205).

The notion of "backlash," with its latent reversibility of the direction of mapping features, deserves further investigation. If the notion makes sense, it would be sensible to pay systematic attention to this mechanism in the metaphors occurring in consumer advertising. While we ostensibly find many consumer goods compared to people, animals, aspects of travel, games, and art, the notion of subsidiary transfer or backlash affects (contaminates) these domains - domains that map our bodily and spiritual identities as human beings. To exaggerate: given enough exposure to computer ads, there may come a moment when we no longer think of the virtual world of computer technology in terms of the actual world of our personal and "natural" environment, but about our daily lives in terms of computer virtuality.

\section{Conclusions}

Let me briefly recapitulate some conclusions that have been drawn in this article.

(1) The 27 pictorial metaphors in the American summer issue (1999) of PC Magazine studied can be accounted for in the theoretical framework proposed by Forceville (1996), although some specimens hover between types.

(2) In a number of cases, a metaphorical construal of the two salient phenomena as target and source respectively appeared to be a possible, but not a necessary strategy to make sense of their juxtaposition. Put differently, sometimes a non-metaphorical analysis instead of, or in addition to, a metaphorical analysis yields a plausible interpretation. Where a non-metaphorical interpretation is possible, it "naturalizes" the metaphor. 
(3) Metaphors in computer ads are frequently personifications; computer technology is conceptualized as mirroring our humanity. As for the non-personified source domains, there seems to be a tendency to choose source domains that stereotypically belong to the world of men rather than of women. I speculate that some domains (art, games, magic) appeal more specifically to computer enthusiasts' self-image as creative wizzards rather than as cool technologists.

\section{Literature}

Black, M. (1962). Metaphor. In: M. Black, Models and metaphors. Ithaca, NY: Cornell UP, 25-47.

Forceville, C. (1995). (A)symmetry in metaphor: the importance of extended context. Poetics Today 16:4, 677-708.

Forceville, C. (1996). Pictorial metaphor in advertising. London/New York: Routledge.

Forceville, C. (1999a). Educating the eye? Kress \& Van Leeuwen's Reading Images: The Grammar of Visual Design, (1996). Language \& Literature, 8:2, 163-78.

Forceville, C. (1999b). The metaphor COLIN IS A CHILD in Ian McEwan's, Harold Pinter's, and Paul Schrader's The Comfort of Strangers. Metaphor and Symbol 14:3, 179-98.

Forceville, C. (1999c). Art or ad? The effect of genre-attribution on the interpretation of images. (Forthcoming, SPIEL)

Johnson, M. (1987). The body in the mind: the bodily basis of meaning, imagination and reason. Chicago: $\mathrm{U}$ of Chicago $\mathrm{P}$.

Kress, G., and T. van Leeuwen (1996). Reading images: the grammar of visual design. London/New York: Routledge.

Lakoff, G. and M. Johnson (1980). Metaphors we live by. Chicago: U of Chicago P.

Sperber, D. and D. Wilson (1986). Relevance: communication and cognition. Oxford: Blackwell (Revised, expanded and updated edition 1995).

Shore, B. (1996). Culture in mind: cognition, culture, and the problem of meaning. New York/Oxford: Oxford University Press.

Steen, G.J. (1994). Understanding metaphor in literature: an empirical approach. London: Longman.

Turner, Mark. (1991). Reading minds: the study of English in the age of cognitive science. Princeton NJ: Princeton UP. 
